Original Article

\title{
DEVELOPMENT AND VALIDATION OF ANALYTICAL METHOD FOR QUANTIFICATION OF ACETIC ACID CONTENT IN AMLODIPINE BESYLATE
}

\section{S. K. MANIRUL HAQUE ${ }^{*}$, AYMAN AHMAD ${ }^{1}$}

1Department of Chemical and Process Engineering Technology, Jubail Industrial College, Jubail Industrial City, P. O. Box No-10099, Zip Code: 31961, Saudi Arabia

Email: Haque_m@jic.edu.sa

Received: 14 Jun 2018 Revised and Accepted: 15 Feb 2019

\section{ABSTRACT}

Objective: To develop and validate a simple and accurate cost-effective titrimetric method according to International Conference Harmonization (ICH) guidelines for acetic acid content in Amlodipine Besylate.

Methods: The titration based on general acid-base reaction to form water and salt. Sodium hydroxide act as a strong base and titrated against weak acid (acetic acid). Phenolphthalein used as an indicator and colorless to pink is the endpoint. Sodium hydroxide is standardized with primary standard potassium hydrogen phthalate.

Results: The method was linear in the range of 0.75 to $30.25 \mu \mathrm{g} / \mathrm{ml}$ with a correlation coefficient 0.9999 . Limit of detection (LOD) and limit of quantitation (LOQ) value were found to be 0.61 and $1.85 \mu \mathrm{g} / \mathrm{ml}$, respectively. The percentage recovery (98.20-99.97\%) and percentage relative standard deviation (\%RSD) is less than $2 \%$ within the acceptable limit of ICH guidelines. The robustness and ruggedness results were excellent. Method is accurate and precise, no interference from excipients.

Conclusion: A new analytical titrimetric method was developed and validated as per ICH guidelines for the determination of acetic acid content in amlodipine. This proposed method applied for routine analysis of acetic acid content in bulk and pharmaceutical formulations of amlodipine besylate.

Keywords: Acetic acid, Amlodipine besylate, Method development, Validation, Tablets

(C) 2019 The Authors. Published by Innovare Academic Sciences Pvt Ltd. This is an open access article under the CC BY license (http://creativecommons.org/licenses/by/4.0/) DOI: http://dx.doi.org/10.22159/ijpps.2019v11i4.31672

\section{INTRODUCTION}

Amlodipine, 3-0-ethyl 5-0-methyl 2-(2-aminoethoxymethyl)-4-(2chlorophenyl)-6-methyl-1,4-dihydropyridine-3,5-dicarboxylate is the calcium channel blocker [1, 2] (fig. 1). Amlodipine is generally applicable for as anti-hypertensive agent as well for the treatment of angina. It is a well-known medication for peripheral vascular resistance that will help to minimize coronary vascular spasm.<smiles>CCOC(=O)C1=C(COCCN)NC(C)=C(C(=O)OC)C1c1ccccc1Cl</smiles>

Fig. 1: Structure of amlodipine

Acetic acid $\left(\mathrm{CH}_{3} \mathrm{COOH}\right)$ is an important component of vinegar and act as mild chelating agent. The other name of acetic acid are methane carboxylic acid, ethylic acid and ethanoic acid. Acetaldehyde used for the preparation of acetic acid, followed by catalytic oxidation. During this synthesis, two byproducts, formaldehyde and formic acid were formed. The chemical exposures can make irritation in nose, cough and throat. The other symptoms are considered headache, vomiting, nausea, eye pain and impaired vision [3-6]. The acetic acid content was amperometrically determined in fermentation broths [7], museum cabinets with ion chromatography [8], fruits juices and drinks with high performance liquid chromatography [9], during hydrothermal treatment of birch wood utilizing gas chromatography [10], pectin samples with gas chromatography-mass spectrophotometry [11] and amlodipine besylate using gas chromatography [12].
Analytical method can be used for routine analysis when it fulfills certain performance criteria. Once the analytical method is advent, it is necessary to decide its suitability for the intended purpose, defined as method validation. Several international organizations and regulatory authorities, the namely international union of pure and applied chemistry, international laboratory accreditation conference, western european laboratory accreditation cooperation, an international conference on harmonization and international organization for standardization are involved to develop and modify the criteria of validation. The important validation parameters are accuracy, precision, selectivity, specificity, limits of detection and quantitation, robustness and ruggedness. However, when a method is validated, the role of statistical analysis cannot be ignored. It is the only way to get the most conclusive results from the mathematical data during the analysis.

The main reason of impurities presents in the final products because of raw materials, intermediates, solvents as well as byproducts during synthetic process. It may be organic impurities or residual solvents. The presence of residual solvents affects the efficacy of drug products. The ICH guidelines showed disadvantages of residual solvent available in the final product and limited it in terms of safety [13-17]. Due to its toxicity behavior [18], it was necessary to adopt a new simple and cost-effective method for the determination of acetic acid. The titrimetric method [19-21] are low cost and easily available in academic and research laboratory. The proposed method was developed and validated for the determination of acetic acid content in pharmaceutical formulations for amlodipine besylate.

\section{MATERIALS AND METHODS}

\section{Materials}

- Acetic acid $\left(\mathrm{CH}_{3} \mathrm{COOH}\right)$ was purchased from Sigma Aldrich, USA.

- Amlodipine pharmaceutical formulations: Amlopine5 (5 mg, Arac Healthcare), Amlor (5 mg, Pzier), Exforge (5 mg, Novartis) were purchased from local market. 
- Sodium hydroxide $(\mathrm{NaOH})$ was purchased from PanReac AppliChem ITW Reagents, Germany.

- $\quad$ Phenolphthalein was purchased from Sigma Aldrich, USA.

- $\quad$ Ethanol was purchased from Carlo Erba Reagents, France.

- Potassium hydrogen phthalate (KHP) was purchased from Sigma Aldrich, USA.

- Double distilled water (Laboratory, Jubail Industrial College, Saudi Arabia).

- All chemicals were of analytical grade.

\section{Solutions}

\section{Sodium hydroxide solution (0.01 M)}

$400 \mathrm{mg}$ of sodium hydroxide transferred into $1 \mathrm{l}$ volumetric flask and diluted upto the mark with distilled water.

\section{Acetic acid solution (0.5 M)}

$24 \mathrm{ml}$ glacial acetic acid (99.9\%) transferred into $1 \mathrm{l}$ volumetric flask and made upto the mark with distilled water.

\section{Phenolphthalein indicator $(0.1 \%)$}

$0.1 \mathrm{~g}$ phenolphthalein transferred into $100 \mathrm{ml}$ volumetric flask, dissolved and diluted with $95 \%$ ethanol.

\section{Procedure}

\section{Standardization}

The sodium hydroxide solution standardized with primary standard potassium hydrogen phthalate. $40.84 \mathrm{mg}$ KHP transferred into a 250 $\mathrm{ml}$ erlenmeyer flask and added $20 \mathrm{ml}$ distilled water to dissolve. Two drops of phenolphthalein $(0.1 \%)$ used as indicator. Titration with sodium hydroxide continued until pink color changed to colorless. The replicate analyses repeated for two more times to get the average volume of sodium hydroxide, used to calculate the exact molar concentration of sodium hydroxide.

\section{General}

The acetic acid in the form of solution transferred $250 \mathrm{ml}$ conical flask. Two drops of phenolphthalein indicator added to the flask and titrated with sodium hydroxide $(0.01 \mathrm{M})$ until the color of the solution changed from pink to colorless and recorded the volume [22]. Different amount of acetic acid and volume of $\mathrm{NaOH}$ applied to construct a calibration curve and adopted a linear equation, which followed the linearity law. The unknown concentration/amount of acetic acid quantified in amlodipine besylate using the linear calibration curve.

\section{Pharmaceutical formulations}

To determine acetic acid content in pharmaceutical dosage form (Amlopine5, Amlor, Exforge label claim: $5 \mathrm{mg}$ amlodipine per tablet/capsule), two tablets grinded and finely powdered using mortar and pestle. Then the powder placed into a 100 volumetric flask containing $50 \mathrm{ml}$ water and sonicated for $5 \mathrm{~min}$, then diluted upto the mark with distilled water. The solution filtered using $0.45 \mu \mathrm{m}$ filter (Millipore, Milford). A $20 \mathrm{ml}$ otest solution used for titration with standard $\mathrm{NaOH}(0.01 \mathrm{M})$ solution in the presence phenolphthalein indicator. The same procedure performed with other pharmaceutical formulations of amlodipine besylate to determine acetic acid content.

\section{Method validation}

\section{Specificity}

The system suitability test will confirm the ability of the proposed method to determine the analyte accurately in a sample matrix in the presence of other components.

\section{Accuracy}

The closeness between the standard values with experimental values found during the analysis. The percentage recovery was important parameter related to accuracy.

\section{Precision}

The closeness between all of the results of replicate analysis were determined for the proposed method. There is no relation with the true value under stipulated conditions.

\section{Limit of detection}

Limit of detection indicates the point how the uncertainty of our results associate with the measured value. The LOD value was not necessary to quantify but this value was the lowest concentration in the sample matrix to be detected.

LOD $=3.3 \times \mathrm{S}_{\mathrm{o}} / \mathrm{b}$ Where $\mathrm{S}_{\mathrm{o}}$ and $\mathrm{b}$ are standard deviation and slope of the standard calibration curve, respectively.

\section{Limit of quantitation}

Limit of quantitation is the highest acceptable precision with lowest concentration of analyte in the sample matrix and quantified.

$\mathrm{LOQ}=10 \times \mathrm{S}_{\mathrm{o}} / \mathrm{b}$

\section{Linearity}

The concentration of analyte was directly proportional to the results of the analysis within a given range.

\section{Linear range}

The peak areas of derivatives formaldehyde standard were directly proportional to the volume of sample over the concentration range. A known confidence level can be established by utilizing the linear calibration model.

\section{Ruggedness}

Small changes in the environment conducted experiments and model of the instrument means little variation with operating conditions as compared to the normal proposed method of analysis.

\section{Robustness}

The proposed analytical method varied with an acceptable limit. The results were unaffected by small changes in the parameters.

\section{RESULTS AND DISCUSSION}

\section{System suitability}

The system suitability test was performed for the proposed method by utilizing $25 \mu \mathrm{g} / \mathrm{ml}$ standard acetic acid solution. The same concentration titrated six times with $\mathrm{NaOH}$ and recorded the volume. The percentage relative standard deviation (\%RSD) was calculated and found it is in the acceptable limit of ICH guideline.

\section{Linearity and range}

The linearity was compliance with the regression plots in the concentration range of $0.75-30.25 \mu \mathrm{g} / \mathrm{ml}$ with a correlation coefficient $\left(\mathrm{r}^{2}\right)$ of 0.9999 . The linear graph between concentrations of $\mathrm{CH}_{3} \mathrm{COOH}$ and volume of $\mathrm{NaOH}$ given in fig. 2. The linearity range, slope, intercept, linear regression equation, limit of detection, limit of quantitation summarized in table 1 and indicated good linearity over the working concentration ranges.

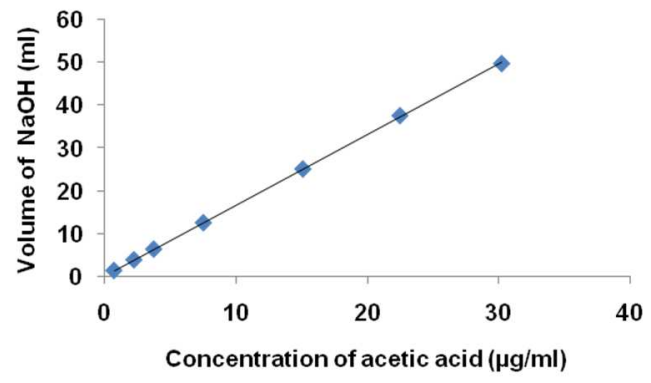

Fig. 2: Linearity plot of the proposed method between the concentration of acetic acid $(\mu \mathrm{g} / \mathrm{ml})$ and volume of $\mathrm{NaOH}(\mathrm{ml})$ 
Table 1: Summary of optical and regression characteristics of the proposed method

\begin{tabular}{ll}
\hline Parameters & Acetic acid \\
\hline Linear dynamic range $(\mu \mathrm{g} / \mathrm{ml})$ & $0.75-30.25$ \\
Regression equation & $\mathrm{y}=1.6517 \mathrm{x}+0.0755$ \\
Correlation coefficient $\left(\mathrm{r}^{2}\right)$ & 0.9999 \\
SD of calibration curve $\left(\mathrm{S}_{\mathrm{o}}\right)$ & 0.112 \\
Slope of calibration curve $(\mathrm{b})$ & 0.605 \\
LOD $(\mu \mathrm{g} / \mathrm{ml})$ & 0.61 \\
$\mathrm{LOQ}(\mu \mathrm{g} / \mathrm{ml})$ & 1.85 \\
\hline
\end{tabular}

\section{Accuracy and precision}

The standard acetic acid solutions $(5,15,25 \mu \mathrm{g} / \mathrm{ml})$ used to determine the accuracy and precision of the proposed method. The results recorded with fresh solutions (intraday) and after seven days (interday). The studies showed good recoveries in the range of $99.20-99.97 \%$ (table 2) and indicating the method accurate. The intermediate precision and repeatability investigation gave excellent results in terms of \%RSD $(0.579-1.70$ $\%$ ) within the limit (table 2).

Table 2: Summary of accuracy and precision results of the proposed method

\begin{tabular}{|c|c|c|c|c|}
\hline \multirow[t]{2}{*}{ Proposed methods } & \multicolumn{2}{|c|}{ Amount $(\mu \mathrm{g} / \mathrm{ml})$} & \multirow[t]{2}{*}{ \% Recovery } & \multirow[t]{2}{*}{ \% RSDa } \\
\hline & Taken & Found $\pm S D^{a}$ & & \\
\hline \multirow[t]{3}{*}{ Intraday } & 5.00 & $4.958 \pm 0.042$ & 99.17 & 0.843 \\
\hline & 15.00 & $14.975 \pm 0.111$ & 99.83 & 0.739 \\
\hline & 25.00 & $24.990 \pm 0.145$ & 99.97 & 0.579 \\
\hline \multirow[t]{3}{*}{ Interday } & 5.00 & $4.909 \pm 0.084$ & 98.20 & 1.70 \\
\hline & 15.00 & $14.878 \pm 0.151$ & 99.19 & 1.01 \\
\hline & 25.00 & $24.823 \pm 0.182$ & 99.29 & 0.734 \\
\hline
\end{tabular}

aMean for five independent analyses, $\mathrm{SD}=\mathrm{Standard}$ deviation, RSD=Relative standard deviation.

\section{LOD and LOQ}

The standard deviation $\left(\mathrm{S}_{0}\right)$, calculated between concentration of acetic acid $(\mu \mathrm{g} / \mathrm{ml})$ and its respective $\mathrm{NaOH}(\mathrm{ml})$ using the linearity data. The LOD and LOQ values evaluated depend on slope (b) of the straight line. The values were 0.61 and $1.85(\mu \mathrm{g} / \mathrm{ml})$ respectively (table 1). The precision of LOD value stidied, since $0.75 \mu \mathrm{g} / \mathrm{ml}$ gave $\mathrm{NaOH}$ volume $1.3 \mathrm{ml}$, therefore carried out precision with $0.5 \mu \mathrm{g} / \mathrm{ml}$, which would give $\mathrm{NaOH}$ volume $1 \mathrm{ml}$, lowest volume had the ability to neutralize the acid content in normal conditions. The \% RSD of acetic acid solution $(0.5 \mu \mathrm{g} / \mathrm{ml}) 16.2 \%$ with five replicate titrated volume of $\mathrm{NaOH}$ and meet the acceptance criteria (NMT 20\%). The \% RSD was calculated 8.85 and $17.25 \%$ with 1.90 and $1.0 \mu \mathrm{g} / \mathrm{ml}$ respectively. Therefore, \%RSD is very low for $1.90 \mu \mathrm{g} / \mathrm{ml}$ compared to $1.0 \mu \mathrm{g} / \mathrm{ml}$. The $\%$ RSD value for $1.0 \mu \mathrm{g} / \mathrm{ml}$ was very close to the acceptance limit of $20 \%$. Therefore, the LOD and LOQ of the method were found to be 0.5 and $1.0 \mu \mathrm{g} / \mathrm{ml}$ respectively.

\section{Robustness}

The robustness study carried out in different laboratories. The system suitability investigated and results were accepted within the limit. The \% RSD (0.582-1.70 \%) were calculated and tabulated in table 3.

Table 3: Summary of robustness of the proposed method

\begin{tabular}{|c|c|c|c|c|}
\hline \multirow[t]{2}{*}{ Proposed methods } & \multicolumn{2}{|c|}{ Amount $(\mu \mathrm{g} / \mathrm{ml})$} & \multirow[t]{2}{*}{ \% Recovery } & \multirow[t]{2}{*}{ \% RSDa } \\
\hline & Taken & Found \pm SD $^{\mathrm{a}}$ & & \\
\hline \multirow{3}{*}{ Lab DL-310 } & 5.00 & $4.96 \pm 0.04$ & 99.20 & 0.84 \\
\hline & 15.00 & $14.98 \pm 0.11$ & 99.87 & 0.741 \\
\hline & 25.00 & $24.99 \pm 0.15$ & 99.96 & 0.582 \\
\hline \multirow[t]{3}{*}{ Lab DL-311 } & 5.00 & $4.91 \pm 0.08$ & 98.20 & 1.70 \\
\hline & 15.00 & $14.88 \pm 0.153$ & 99.20 & 1.01 \\
\hline & 25.00 & $24.84 \pm 0.18$ & 99.36 & 0.75 \\
\hline
\end{tabular}

aMean for five independent analyses, $\mathrm{SD}=$ Standard deviation, RSD=Relative standard deviation.

\section{Ruggedness}

Ruggedness studies of the proposed method performed by selecting three concentration levels within the linearity range. The test result was expressed in terms of \%RSD, applied the same procedure by two analyst using different burettes. The \%RSD values were less than $2 \%$ for the developed method. These results showed excellent ruggedness value of the method (table 4).

Table 4: Summary of the ruggedness of the proposed method

\begin{tabular}{|c|c|c|c|c|}
\hline \multirow[t]{2}{*}{ Proposed methods } & \multicolumn{2}{|c|}{ Amount $(\mu \mathrm{g} / \mathrm{ml})$} & \multirow[t]{2}{*}{ \% Recovery } & \multirow[t]{2}{*}{ \% RSD } \\
\hline & Taken & Found $\pm S D^{a}$ & & \\
\hline \multirow[t]{3}{*}{ Burette A } & 5.00 & $4.945 \pm 0.068$ & 98.90 & 1.370 \\
\hline & 15.00 & $14.993 \pm 0.104$ & 99.95 & 0.690 \\
\hline & 25.00 & $24.995 \pm 0.117$ & 99.98 & 0.469 \\
\hline \multirow[t]{3}{*}{ Burette B } & 5.00 & $4.945 \pm 0.068$ & 98.90 & 1.370 \\
\hline & 15.00 & $14.970 \pm 0.135$ & 99.80 & 0.905 \\
\hline & 25.00 & $24.927 \pm 0.244$ & 99.71 & 0.979 \\
\hline \multirow[t]{3}{*}{ Analyst 1} & 5.00 & $4.942 \pm 0.066$ & 98.84 & 1.326 \\
\hline & 15.00 & $14.992 \pm 0.100$ & 99.95 & 0.668 \\
\hline & 25.00 & $24.901 \pm 0.065$ & 99.60 & 0.261 \\
\hline \multirow[t]{3}{*}{ Analyst 2} & 5.00 & $4.986 \pm 0.076$ & 99.71 & 1.518 \\
\hline & 15.00 & $14.861 \pm 0.100$ & 99.22 & 0.673 \\
\hline & 25.00 & $24.945 \pm 0.078$ & 99.78 & 0.313 \\
\hline
\end{tabular}

aMean for five independent analyses, $\mathrm{SD}=$ Standard deviation, $\mathrm{RSD}=$ Relative standard deviation. 


\section{Solution stability}

The solutions kept for seven days and performed the analysis every day. The \% RSD was calculated with five replicate values of the same concentration. It was found that the solutions were stable and suitable for the analysis after $7 \mathrm{~d}$ because calculated \% RSD values were in the range of ICH limit (2\%).

\section{Acetic acid content in pharmaceutical formulations}

The formulation samples were titrated with standard $\mathrm{NaOH}$ solution. No color change and endpoint were not detected. Therefore, acetic acid content are not available with the present pharmaceutical formulations of amlodipine besylate and result is similar to developed gas chromatographic method [12].

\section{CONCLUSION}

The analytical method for the estimation of acetic acid in amlodipine besylate has been successfully validated. The proposed method for pharmaceutical formulation does not require any cleanup procedure for the analysis,. It has a wider linear dynamic range with good accuracy and precision. It is a simple and accurate time-consuming method, whereas there is no official method for its determination. The \%RSD value was obtained, accurate and within the acceptable limit of ICH guidelines. Thus the present method is satisfactorily a better method for the determination of acetic acid content in the pharmaceutical dosage form of amlodipine besylate

\section{AUTHORS CONTRIBUTIONS}

SK Manirul Haque: Formulated the study, helped in literature searches, wrote the first draft, gave the answer of all reviewers comment and approved the final version to be submitted.

Ayman Ahmad: Managed literature survey, performed all experiments, collected data and approved the final version to be submitted.

\section{CONFLICT OF INTERESTS}

The authors report no conflicts of interest

\section{REFERENCES}

1. British Pharmacopoeia. Vol. 1. London: The Stationery office Publications; 2007. p. 132-4.

2. Tripathi KD. Essentials of medical pharmacology. 5th Edition. Jaypee Brothers Medical Publishers (P) Ltd; 2003. p. 488, 496, 497.

3. Dziezak JD. Acids/natural acids and acidulants. 2nd ed. Encyclopedia of food sciences and nutrition; 2003. p. 12-7.

4. Williams FN, Lee JO. Chemical burns. $5^{\text {th }}$ ed. Total Burn Care; 2018. p. 408-13.

5. Mackison FW, Stricoff RS, Partridge LJJr. NIOSH/OSHAoccupational health guidelines for chemical hazards. Vol. 3. DHHS (NIOSH) Publication No. 81-123 Washington, DC: U. S. Government Printing Office; 1981. p. 2.

6. Bingham E, Cohrssen B, Powell CH. Patty's toxicology. $5^{\text {th }}$ ed. Vol. 1-9. John Wiley and Sons. New York, NY; 2001. p. V5, 703.
7. Hikuma M, Kubo T, Yasuda T. Amperometric determination of acetic acid with immobilized trichosporon brassicae. Anal Chimi Acta 1979;109:33-8.

8. Gibson LT, Cooksey BG, Littlejohn D, Tennent NH. A diffusion tube sampler for the determination of acetic acid and formic acid vapours in museum cabinets. Anal Chim Acta 1997;341:11-9.

9. Shui G, Leong LP. Separation and determination of organic acids and phenolic compounds in fruit juices and drinks by high-performance liquid chromatography. J Chromatogr A 2002; 977:89-96.

10. Sundqvist B, Karlsson O, Westermark U. Determination of formic acid and acetic acid concentrations formed during hydrothermal treatment of birch wood and its relation to colour, strength and hardness. Wood Sci-Tech 2006;40:549.

11. Savary BJ, Nunez A. Gas chromatography-mass spectrometry method for determining the methanol and acetic acid contents of pectin using headspace solid-phase microextraction and stable isotope dilution. J Chromatogr A 2003;1017:151-9.

12. Kumar VA, Aravind G, Srikanth I, Srinivasarao A, Raju CD. Novel analytical method development and validation for the determination of residual solvents in amlodipine besylate by gas chromatography. Der Pharma Chem 2012;4:2228-38.

13. International council for harmonization of technical requirements for pharmaceuticals for human use, Impurities: the guideline for residual solvents, ICH Q3C(R7); 2018.

14. United States Food and Drug Administration. Guidance for industry: Validation of analytical procedures: methodology Q2B; 1996.

15. United States Food and Drug Administration. Guideline for industry: text on validation of analytical procedures: ICH Q2A; 1995.

16. International conference on the harmonization of the technical requirements for registration of pharmaceuticals for human use. Validation of analytical procedures: text and methodology ICH Q2(R1); 1996.

17. Sayeeda S, Balaji N. Simultaneous trace level determination of benzene and 1,2-dichloroethane by GC-HS/GC-MS in several pharmaceutical drug substances. Int J Appl Pharma 2019:11:82-8.

18. Devesh K. Impact of pharmaceutical industries on the environment, health and safety. J Crit Rev 2015;2:25-30.

19. Pol PA, Mehta PP. Titrimetric analysis of ibuprofen bulk drug sample by using urea as a hydrotropic solubilizing agent. Int J Curr Pharm Res 2015;7:76-7.

20. Tambe VD, Tambe VB, Jadhav RS. Evaluation of leucas aspera whole plant extracts for diuretic and laxative property. Asian J Pharm Clin Res 2016;9:118-21.

21. Sampatti P, Preeti M, Bhagwat C. Quantitative analysis of the salicylic acid bulk sample using hydrotropic solubilizing agents. Asian J Pharm Clin Res 2016;9 Suppl 1:168-9.

22. Jennings PA, Mullen CA, Roy Melinda. Titration and $\mathrm{pH}$ measurement. In: Encyclopedia of life sciences (ELS). John Wiley and Sons, Ltd: Chichester; 2010. Doi:10.1002/ 9780470015902.a0002700.pub2. 